\title{
An Examination Of Accounting Majors' Ethical Decisions Before And After An Ethics Course Requirement
}

Violet Rogers, Stephen F. Austin State University Aileen Smith, Stephen F. Austin State University

\begin{abstract}
The increased focus on ethical decision making in the accounting profession has resulted in greater attention being paid to the education of future accountants. Texas is one of the states that requires a State Board approved university course in Accounting Ethics to be on the transcript of prospective CPA candidates. This study reports on research using senior/graduate level accounting majors at a Texas state university before the university course requirement and after the requirement. The survey presented four vignettes for the students to consider (i.e., 2 describe an ethical decision and 2 describe an unethical decision). Students were requested to indicate (1) how ethical/unethical they believed the actions described were and (2) the probability that they would take the same action as the actor. The results of the analysis indicate no significant differences in the responses of the students whenever the vignette describes a situation in which the accountant makes an ethical decision. However, significant differences were indicated in both decisions whenever the students were dealing with a vignette describing an accountant making an unethical decision.
\end{abstract}

Keywords: ethics, students, university course, ethical decision making

\section{INTRODUCTION}

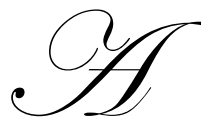

s of July 1, 2005, the Texas Board of Public Accountancy requires that three hours of credit be earned and reported on the transcript on the topic of ethics in order to sit for the CPA exam. The ethics course must include ethical reasoning, integrity, objectivity and independence. The approval process is initiated when the University submits the course syllabus and Instructor name and credentials. The syllabus is reviewed by the State Board for inclusion of the aforementioned topics. If the course is approved the University is notified, and the Courses and the instructor are listed on the Texas State Board of Accountancy's website.

Other requirements for Texas candidates include holding a baccalaureate degree from a recognized educational institution, with at least 21 hours of upper division being devoted to related business courses. The candidate must also have complete 150 semester hours with at least 30 hours of accounting courses taught above the principles (introductory) level. CPA review courses are not considered accounting courses and only 3 hours of approved internships may count.

The addition of the ethics course and content specifications were initiated by the State Board. Previously, ethics and board rules coverage were part of accounting curriculum, but the coverage often receives only a couple of weeks of coverage. Other entities such as business accrediting bodies have also encouraged teaching ethics to business students.

Because ethical beliefs and actions are developed over a lifetime, it is important to reinforce ethical concepts because they can be positively or negatively affected by the environment. Thus teaching ethics courses 
and subsequent Continuing Professional Education requirements in Ethics after certification have been added over the years to reinforce our ethical beliefs. Now the question becomes, "Do they work"?

\section{LITERATURE REVIEW}

The increased focus on ethics education in accounting has prompted a number of research studies to look at whether integrating an ethics module or a separate ethics course is making a difference. Whether ethics can be taught at the university level continues to be a relevant topic for discussion and research. Several researchers have attempted to address the topic with relatively positive results.

Using a pre- and post-test design with control and experimental groups, Hiltebeitel and Jones (1991) studied the impact of using an integrated ethics module in an auditing class. While no significant changes were indicated on the personal ethical decisions, improvement in the rankings on the professional ethical decisions did occur. These results suggest ethics instruction may have a positive effect on accountants' ethical decision resolution.

Using 59 accounting and non-accounting major business students, Green and Weber (1997) examined the influence of the AICPA Code of Conduct (Code) on the ethical beliefs of future accountants. The results provide evidence that the exposure to the Code improves accounting students' ability to make better ethical choices.

Ward and Ward (1996), using a four-scenario instrument, surveyed 54 accounting students. Using a preand post-test design, students were tested concerning the course content as it related to the professional Code. The results indicated that the course inclusion of the Code is shown to be effective in helping students address ethical dilemma decisions.

Esmond-Kiger (2004) requested first-class-day Intermediate II students to write a 2- to 3-page reflective essay after reading both positive and negative news articles related to ethical behavior in accounting. A similar follow-up assignment was given the last week of the semester. Ethical instruction and discussions were integrated into the course. The feedback from the assignments indicated a greater appreciation and internalization of ethical behavior and decision-making in school, in future careers, and in their personal lives. An additional survey was used with students from the year 2000 (pre-Enron) and 2003 (post-Enron) time periods. Students were asked to respond regarding willingness (1) to leave a job related to unethical occurrences and (2) to report unethical behavior of peer or supervisor. Students from the 2003 group were more willing to act in both situations.

Hiltebeitel and Jones (1992) assessed the responses of student business majors to 14 principles of ethical conduct. All of the students answered a pre- and post-test. The treatment group completed an in course ethics unit (e.g., text materials, videos, articles, and cases). The results of the analysis indicated significant positive changes in the responses of the treatment group on four of the 14 principles.

Arlow and Ulrich (1983) initially reported increased ethical awareness after business students were exposed to an ethics component integrated into the course. Four years later, their follow-up study indicated a decline in the ethical awareness of the group.

Other researchers have reported limited to no significant differences in the students' studies. Lampe (1996) surveyed students enrolled in Accounting Information Systems courses and Auditing courses to measure the potential impact of adding ethical content, cases, and discussions to intermediate-level classes taken between the two classes. Overall, the results indicated no significant changes in the moral development level of the students studied. The Auditing students did, however, rank "code-implied decision rules" as the most important for ethical decision making.

In a study of accounting students from ten state and private universities, McCarthy (1997) examined whether exposure to the Code of Professional Conduct had a positive effect on the ethical orientation of the students. 
Using a pre- and post-professional code coverage survey, the results indicated no significant difference between the two groups of accounting students.

The assumption supporting the rationale for providing university accounting ethics instruction is that the participating individuals' ethical and professional code sensitivity can be enhanced. Members of the academic accounting community have stressed that research is needed to determine whether ethics courses in accounting can be effective (Bean and Bernardi, 2005). This assumption points to the following question of interest by this research: Can a separate accounting ethics course translate into more ethical decisions within an accounting environment context?

\section{METHODOLOGY}

A questionnaire containing four scenarios concerning potentially unethical accounting issues was used with two groups of students. The nature of the scenarios keeps the focus on accounting decisions. One group of students took the questionnaire before the State Board requirement of a three hour ethics course and one group of students took the questionnaire after the State Board requirement.

\section{Students}

Two groups of students were surveyed by the questionnaire. One group graduated from the University during 2003 before the Texas State Board of Accountancy passed the law requiring a three-hour Accounting Ethics course be on the university transcript of those candidates sitting for the CPA exam in Texas (effective July 1, 2005). The second group of students was enrolled in a degree program through the Department of Accounting at the University since the separate ethics course requirement in 2005. Their degree requires the Accounting Ethics course during the senior year of their program.

Comparable accounting major students were used for the treatment and control groups. The research of Rest has pointed out the potential effect of age on the moral development scores of individuals. T-test indicates no significant differences between the ages of the two groups used by the study $(t=.99 ; \mathrm{p}=.33)$.

\section{Questionnaire}

The questionnaires were answered by intact classes for a nominal amount of semester points. Students were granted individual confidentiality of response information for the analysis. The use of the scenarios in the current research keeps the accounting environment the specific focus of the study.

The questionnaire presented four scenarios concerning potentially unethical accounting issues. Scenarios 1 and 2 were adapted from DeZoort and Lord (1994); Scenarios 3 and 4 were adapted from Flory et al. (1992, 299300). After reading each scenario, the students were requested to answer two specific questions: (1) In your opinion, how unethical/ethical was the individual's actions? (Using a Likert scale of $1=$ very ethical to $6=$ very unethical) and (2) What is the likelihood that you would take the same action as the individual? $(1=$ very likely to 6 very unlikely). General demographic information was requested from the students and is shown in Table 1.

\begin{tabular}{|l|c|c|}
\hline \multicolumn{3}{|c|}{ Table 1 - Respondent Demographics } \\
\hline Age: & $\mathrm{n}^{*}$ & \\
$\leq 24$ years & 82 & $73 \%$ \\
$\geq 25$ years & $\underline{31}$ & $\underline{27 \%}$ \\
Total & 113 & $400 \%$ \\
\hline Gender: & 46 & $\underline{60 \%}$ \\
Female & $\underline{69}$ & $100 \%$ \\
Male & $\frac{115}{2}$ \\
Total & Not all respondents answered all demographic questions. \\
\hline
\end{tabular}


The use of scenarios or vignettes has become popular in ethical studies because it allows the researchers to exert some control on the focus of the questionnaire (Lampe \& Finn, 1992). After a study examining business ethics, Cavanaugh and Fritzsche (1985) determined that the incorporation of scenarios in survey research provided advantages over other methods. The ego-incorporating nature of the ethical survey items is another potential problem with ethics research. The anonymous response mechanism addresses the potential problem that can result when ego involvement produces halo effects (Flory et al., 1992). Two forms of the questionnaire were used. Form "X" ("Y") used a masculine (feminine) name for the actor in Scenario \#1, feminine (masculine) for Scenario \#2, masculine (feminine) for Scenario \#3, and feminine (masculine) for Scenario \#4.

The scenarios used by the study are constructed to either closely parallel a rule/professional law (i.e., explained in the Code of Professional Conduct or financial accounting and/or auditing principles) or a more ambiguous ethical situation (i.e., a situation not covered by a specific code or standard). Figure 1 provides a condensed identification of the four scenarios. Vignettes 1 and 4 are designed to provide ethical considerations related to previously mentioned rules or principles. Since vignettes 1 and 4 describe direct violations, all of the accounting majors are expected to answer similarly. Vignettes 2 and 3 do not contain situations related to specific guidance from the Code. Since scenarios 2 and 3 are more ambiguous "gray areas," they may produce greater variability.

\begin{tabular}{|c|l|c|}
\hline \multicolumn{3}{|c|}{ Figure 1 - Four Scenarios } \\
\hline Item No. & \multicolumn{1}{|c|}{ Scenario Description } & Action Taken \\
\hline 1 & Filing an accurate/inaccurate CPE report with the State Board; filed an accurate report & ethical \\
2 & Reporting suspicion of potential inventory manipulation; reported suspicion to audit manager & ethical \\
3 & Questionable credit extension; grants credit & unethical \\
4 & Manipulation of accounting records to meet earnings forecast; "cooks the books" & unethical \\
\hline
\end{tabular}

Scenario \#1 described a Certified Public Accounting (CPA) who, in the process of renewing his/her CPA license was notified that s/he lacked Continuing Professional Education hours required for license renewal (required by Bylaw 2.3.3). S/he is faced with filing an untruthful report versus a truthful report. The consequences of filing an untruthful report include lying about the situation, which is an act discreditable to the profession (Rule 501). Scenario \#1 describes that the CPA takes the ethical action and files a truthful report.

A staff auditor, in Scenario \#2, observed that the accountant from the company that s/he was auditing accompanied him/her and recorded tagged items that were to be counted in the inventory test count. S/he was concerned that the company accountant might try to falsify the count. His/her ethical decision was whether or not $\mathrm{s} /$ he should report the suspicious behavior to someone in charge of the audit. The scenario describes that the staff auditor takes the ethical action and reports suspicious behavior. Reporting suspicious behavior is related to the General Standards described in the Code of Professional Conduct.

Scenario \#3 describes an assistant controller who is faced with granting a questionable credit decision for an old friend. The company s/he works for has strict credit policies. If the assistant controller approves credit for the old friend, it will probably be a violation of the strict policies. However, if s/he approves the credit, the company sales will increase, and s/he will meet earnings forecasts and receive a bonus. S/he has a daughter accepted into Medical School and needs the money. Scenario \#3 describes that the assistant controller takes the unethical action and grants credit to the old friend. Making ethical decisions is related to the General Standards described in the Code of Professional Conduct.

In Scenario \#4 a company controller is asked by his/her boss to make/include erroneous accounting entries for the purpose of meeting earnings forecasts. Courts might consider such making/inclusion as fraud. Such actions would be a violation of Rule 102 (Integrity and Objectivity) and Rule 501 (Acts Discreditable). The scenario describes that the company controller makes the unethical decisions to falsify records. 


\section{Analysis Of Data}

T-test analysis was conducted to examine the data for differences between the two groups of students. Table 2 gives the mean responses by student group, as well as information about the type of action taken by the actor in each scenario. For the "A" decisions (how unethical/ethical are the actions?), the lower (higher) the mean, the greater the ethical (unethical) belief expressed by the students (Likert scale where $1=$ very ethical to $6=$ very unethical). Since the first two scenarios provide "ethical" actions, a low response mean was expected. For the last two scenarios, high response means are expected because the actor makes an unethical decision (Likert scale where $1=$ very likely to $6=$ very unlikely). For the "B" decisions (What is the likelihood that you would take the same action?), the lower (higher) the mean, the greater (lower) the belief in the likelihood of making the same decision. Since the first two scenarios provide "ethical" actions, a low response mean is expected; for the last two scenarios that describe "unethical" actions, a high response mean is expected. Decision 1 and 4 were based on quotable rules (Rule 102 and 501.) Decisions 2 and 4 were based on grayer violations of the General Standards.

Table 2 reports mean responses by student groups. On decisions 1 and 2 (ethical decisions), lower mean was expected after the implementation of an ethics course (EC) as compared to before the ethics course (NC). On decisions 3 and 4 (unethical decisions), higher means were expected after the implementation of the ethics course (EC) as compared to before the ethics course (NC).

As indicated on Table 2, the means moved in the expected direction in all scenarios except \#2 which was related to inventory manipulation. Thus evaluating an actor's ethical decision making is not as difficult as evaluating an unethical decision.

Table 3 gives the results of the t-test analysis of the response means. There are no differences in the decisions by the two student groups on the decisions requested from scenarios 1 and 2, the scenarios which described ethical decisions by the actors. However, highly significant differences were revealed by the responses to scenarios 3 and 4 , which described unethical decisions by the actors. This may indicate that it is relatively easy to evaluate an actor's ethical behavior, but it is more problematic when evaluating unethical behavior without training in ethical decision making and the Code of Conduct.

\section{LIMITATIONS}

The experiment used a Pre-Post-Test DIT design. While a Pre-Post-Test design does produce an objective measure for comparison, it is possible that students have been sensitized to ethical topics especially when unethical behavior is questioned. Additionally, volunteers were used for the experiment. Thus, they self-selected to participate in an ethics experiment. Additionally, the actors and scenarios may have produced a measure of intent with regards to accounting decisions, but perhaps not a measure of general intent.

\begin{tabular}{|c|c|c|c|c|}
\hline \multicolumn{5}{|c|}{ Table 2 - Mean Responses by Student Groups } \\
\hline \multirow[t]{2}{*}{ Item No. } & \multicolumn{4}{|c|}{ Mean Responses } \\
\hline & No Ethics Course $(\mathrm{NC})^{\mathrm{a}}$ & Ethics Course $(\mathrm{EC})^{\mathrm{a}}$ & Ethical Decision & Scenario Action \\
\hline $\mathrm{D}_{1} \mathrm{~A}^{\mathrm{d}}$ & 2.0449 & 1.8846 & Rule- & \\
\hline $\mathrm{D} 1 \mathrm{~B}^{\mathrm{e}}$ & 2.0562 & 1.9231 & based & Ethical $^{\mathrm{b}}$ \\
\hline $\mathrm{D} 2 \mathrm{~A}^{\mathrm{d}}$ & 1.8750 & 1.8846 & General Standards & \\
\hline $\mathrm{D} 2 \mathrm{~B}^{\mathrm{e}}$ & 1.9432 & 2.0000 & & Ethical $^{\mathrm{b}}$ \\
\hline $\mathrm{D}^{2} \mathrm{~A}^{\mathrm{d}}$ & 3.7416 & 4.7692 & General Standards & \\
\hline $\mathrm{D} 3 \mathrm{~B}^{\mathrm{e}}$ & 3.8539 & 5.0385 & & Unethical $^{\mathrm{c}}$ \\
\hline $\mathrm{D}_{4} \mathrm{~A}^{\mathrm{d}}$ & 4.7079 & 5.4231 & Rule- & \\
\hline $\mathrm{D} 4 \mathrm{~B}^{\mathrm{e}}$ & 4.3483 & 5.4231 & based & Unethical $^{\mathrm{c}}$ \\
\hline \multicolumn{5}{|c|}{$\begin{array}{l}{ }^{a} N C=\text { no accounting course; } E C=\text { accounting ethics course } \\
{ }^{b} \text { The actor in the scenario makes an ethical decision. } \\
{ }^{c} \text { The actor in the scenario makes an unethical decision. } \\
{ }^{d} \text { For the "A" Decisions - The lower (higher) the mean, the greater the ethical (unethical) belief expressed by the } \\
\text { students. } \\
{ }^{e} \text { For the " } B \text { " Decisions - The lower (higher) the mean, the greater (lower) the belief in the likelihood of making the same } \\
\text { decision. }\end{array}$} \\
\hline
\end{tabular}




\begin{tabular}{|c|c|c|l|}
\hline \multicolumn{3}{|c|}{ Table 3 - Significant t-test Decision Results for Student Groups } \\
\hline Item & t-statistic & p-value & \multicolumn{1}{c|}{ Results* } \\
\hline D3A & 3.98 & .0003 & $\begin{array}{l}\text { NC group believed the actor's unethical decision is more ethical } \\
\text { than EC group } \\
\text { D3B }\end{array}$ \\
\hline D4A & 3.12 & $<.0001$ & $\begin{array}{l}\text { NC group indicated a greater likelihood of taking the same } \\
\text { unethical action than the EC group }\end{array}$ \\
D4B & 4.01 & $\begin{array}{l}\text { NC group believed the actor's unethical decision is more ethical } \\
\text { than EC group } \\
\text { NC group indicated a greater likelihood of taking the same } \\
\text { unethical action than the EC group }\end{array}$ \\
\hline$* N C=$ no accounting ethics course; EC = accounting ethics course
\end{tabular}

Other influences, other than an ethics course, may have contributed to the results. Rest suggests that those individuals who chose to participate in higher education may be those who are more likely to seek academic stimulation and are motivated toward self improvement (1986, 34-35). This may also be part of what is beings measured in the research results.

\section{CONCLUSION}

The survey results indicate that Ethics courses may be resulting in better ethical decision making. Perhaps alerting students to ethical violations is making them more aware of their decisions in the workplace. The results indicate that requiring an ethics course does make an immediate (albeit perhaps short term) difference in ethical decision making or in assessing potential ethical/unethical behavior.

\section{REFERENCES}

1. Arlow, P., and Ulrich, T.A. 1983. Can Ethics be Taught to Business Students? The Collegiate Forum, spring, 16-23.

2. Bean, D.F., and Bernardi, R.A. 2005. Accounting Ethics Courses: A Professional Necessity. CPA Journal, 75 (12), 64-65.

3. Cavanaugh, G.F., and Fritzsche, D.J. 1985. Using Vignettes in Business Ethics Research. Research in Corporate Social Performance and Policy, Greenwich, CT: JAI Press, Inc.

4. DeZoort, F.T., and Lord, A.T. 1994. An Investigation of Obedience Pressure Effects on Auditors' Judgments. 1994 Frontiers of Behavioral Research Collected Papers.

5. Esmond-Kiger, C. 2004. Making Ethics A Pervasive Component of Accounting Education. Management Accounting Quarterly, 5 (4), 42-52.

6. Flory, S.M., Phillips, T.J., Jr., Reidenbach, R.E., and Robin, D.P. 1992. A Multidimensional Analysis of Selected Ethical Issues in Accounting. The Accounting Review, 67 (2), 284-302.

7. Green, S., and Weber, J. 1997. Influencing Ethical Development: Exposing Students to the AICPA Code of Conduct, Journal of Business Ethics, 16, 777-790.

8. Hiltebeitel, K.M., and Jones, S.K. 1992. An Assessment of Ethics Instruction in Accounting Education. Journal of Business Ethics, 11, 37-46.

9. Hiltebeitel, K.M., and Jones, S.K. 1991. Initial Evidence on the Impact of Integrating Ethics into Accounting Education. Issues in Accounting Education, 6 (2), 262-275.

10. Lampe, J. 1996. The Impact of Ethics Education in Accounting Curricula. Research on Accounting Ethics, 2, 187-220.

11. Lampe, J., and Finn, D.W. 1992. A Model of Auditors' Ethical Decision Processes. Auditing: A Journal of Practice \& Theory, 11, 33-59.

12. McCarthy, I.N. 1997. Professional Ethics Code Conflict Situations: Ethical and Value Orientation of Collegiate Accounting Students. Journal of Business Ethics, 16, 1467-1473.

13. Rest, J.R. 1986. Moral Development: Advances in Research and Theory. New York: Praeger Publishers.

14. Ward, S.P., and Ward, D.R. 1996. The Code of Professional Conduct: Instructional Impact on Accounting Students' Ethical Perceptions and Attitudes. Journal of Education for Business, 71 (3), 147-150. 